\title{
Cezarean Hysterectomy, A lifesaving Procedure that Albanian Obstetricans Must Be Familiar With
}

\author{
Leon Kaza ${ }^{1}$, Senad Halluni ${ }^{2}$, Rustem Celami ${ }^{*}$, Zef Delia ${ }^{4}$ \\ ${ }^{1}$ Obstetrician and Gynecologist, Maternity of Lezha Regional Hospital, Lezha, Albania \\ ${ }^{2}$ Obstetrician and Gynecologist, Maternity of Shkodra Regional Hospital, Shkodra, Albania \\ ${ }^{3,4}$ Obstetrician and Gynecologist, Service of Obstetrics and Gynecology, American Hospital, Tirana, Albania and \\ *Professor of Obstetrics and Gynecology, Faculty of Technical Medical Sciences, University of A. Xhuvani, Elbasan, \\ Albania \\ *Corresponding author: Prof. Asoc.Dr. Rustem Celami, rustem.celami@uniel.edu.al
}

\begin{abstract}
Cezarean Hysterectomy refers to emergency peripartum hysterectomy - EPH, which is performed as a life saving procedure in cases of continual obstetric hemorrhage secondary to uterine atony, uterine rupture, placental disorders, fibroids, and lacerations during cesarean section - CS or vaginal parturition. Emergency peripartum hysterectomy - EPH, although rare in modern obstetrics, remains a lifesaving procedure in cases of severe hemorrhage. In contemporary obstetrics, overall incidence of severe postpartum hemorrhage was reported to occur in 6.7/1,000 deliveries worldwide. It is one of the leading causes of maternal mortality and morbidity and represents the most challenging complication that an obstetrician will face. The incidence of peripartum hysterectomy in the literature is reported as $0.24,0.77,2.3$, and 5.09 per 1,000 deliveries by many authors mentioning a few; Sakse et al., Whiteman et al., Bai et al., and Zeteroglu et al., respectively. Nevertheless, there is a lack of Albanian data on EPH. To our knowledge, there is no Portuguese information on postpartum hemorrhage and EPH, which does not mean that we do not have suc obstetrical complication and therefore such emergency intervention. This paper's intention is to bring awareness of such catastrophic obstetrical complication especially in young primigavida and primipara women.
\end{abstract}

Keywords: Cezarean hysterectomy, postpartum hemorrhage, maternal, mortality, morbidity 


\section{Introduction}

Emergency peripartum hysterectomy - EPH is an infrequent obstetric procedure, usually performed as a life saving measure in cases of intractable obstetric hemorrhage. ${ }^{1,2,3}$ It was first proposed in 1869 but with no desirable results. ${ }^{4}$ Nonetheless, seven years later in1876, the first cesarean subtotal hysterectomy was carried out successfully, with the result that both the mother and the baby survived..$^{1,5}$

Emergency postpartum hysterectomy - EPH is defined as hysterectomy performed within 24 hours of vaginal or cesarean delivery. ${ }^{1,9,10,11}$ The most frequent indication for EPH in numerous studies was uterine atony, followed by morbid adherence of placenta and uterine rupture. $6,7,8$ There has been a significant change in the indication of EPH over time and from one region to another. Usually, uterine atony was the most common indication for hysterectomy. ${ }^{6-8}$ Recent studies have indicated that abnormal placentation is replacing uterine atony as the most common indication for EPH. ${ }^{5-8}$ The rate of peripartum hysterectomy, not limited to emergent cases, is increased from 1994 to 2017 in the United States and according to Bateman et al. indicated that this increase could be attributed to the rising rate of $\mathrm{CS} .{ }^{12}$ The international recommendations for post partum hemorrhage management including the administration of oxytocin and ergometrine preparations as first line medical management in all cases.

Originally the indications for periparturm hysterectomy included uterine sepsis like amnionitis, chorioamnionitis after prolonged labour, atonia uteri or uncontrollable hemorrhage from placenta site, cancer of the cervix, extensive atresia of the vagina, preventing discharge of lochia, cases of ruptured uterus where suturing would be unsafe, uterine fibroids and tuberculosis. ${ }^{13}$

\section{Discussion}

The first documented hysterectomy on a patient at Caesarean section was performed in United States by Horatio Storer in 1869, although, uterus was removed successfully, tpatient died in 68 hours after surgery. ${ }^{13}$ James Blundell in 1823 based his opinion approving post-cesarean hys- terectomy on work done with rabbits. ${ }^{14}$

In 1876, Eduardo Porro of Milan described the first cesarean hysterectomy in which both mother and baby survived, his patient was a primiparous dwarf, J. C., who was 25 years of age and was only $144 \mathrm{~cm}$ in height. ${ }^{15}$ In his procedure, the uterus was opened in situ and the child was removed alive. After removal of the placenta, an instrument called a cintrat's constrictor was passed over the neck of the uterus and the wire was sufficiently tightened to control hemorrhage and the uterus was then cut away. The stump was brought out through the abdominal wound which was closed with sutures of silver wire. ${ }^{15}$

EPH is a lifesaving procedure, particularly in cases of persistent obstetrical hemorrhage after delivery and this procedure has been advocated by obstetricians for over 100 years.

The most recent population level study shows a peripartum hysterectomy rate of nearly one per 1000 deliveries in the United States. ${ }^{16}$ In addition to abnormal placentation, other significant risk factors for peripartum hysterectomy include advanced maternal age and parity, multiple gestations, antepartum bleeding, preeclampsia, bleeding disorders, and the use of assisted reproductive technologies. ${ }^{17-22}$ While the majority of patients with these risk factors will experience neither major hemorrhage nor hysterectomy, patients who have multiple risk factors or a history of prior postpartum hemorrhage should deliver in a setting where hysterectomy is readily available if needed.

There are numerous risk factors that can contribute for this entity and recognizing and assessing patients at risk is very important. Also, appropriate management of cases of postpartum hemorrhage is an important issue. Ideally each labor and delivery unit has a postpartum hemorrhage protocol for patients with estimated blood loss exceeding a predefined threshold, often $1000 \mathrm{~mL}$. These protocols provide a standardized approach to evaluating and monitoring the patient, notifying a multidisciplinary team, and treatment.

Some of these features that pose the difficulties with obstetric hysterectomy include; Often markedly enlarged and distended uterine and ovarian 
vessels. There is generally increased blood supply to the pelvic organs in pregnancy. Pelvic tissues adjacent to the uterus are oedematous and friable. Trauma of extensive uterine rupture gives rise to gross distortion of the anatomy and edema of the area surrounding the site of rupture. Placenta previa percreta may extend into the bladder and other pelvic organs. Scarring from previous cesarean sections obliterates the utero-vesical space and makes the separation of the bladder from the uterus difficult and injury prone. The ureters may be sectioned, clamped or stitched because often, heavy bleeding interferes with proper exposure. Difficulty in identifying the vaginal angles or the cervix to complete a total hysterectomy in laboring patients where the cervix is fully dilated. The decision to perform hysterectomy is difficult especially in nulliparous women as this brings an abrupt and unwelcome end to their reproductive career. However the delayed decision may cause more blood loss thereby increasing morbidity.

In conlusions: Posptpartum hemaoragy poses a dangerous process that include radical interventions like hysterectomy wich possesses complications itself not only as radical procedure but also as other processes of pregnancy and mode of delivery, patients conditionas and other pathologies involved. Thus, a carefull evaluation, and abnormal placental insertion, ealy diagnosis of posptpartum hemorrhage and proper management as multidisiplanry team is required. This is a procedure that we all obstetrician must be familiar with and especially in regional and city hospitals where infrastructure and human resources team is not always available in Albania.

\section{References}

1. D. W. Sturdee and D. I. Rushton, "Caesarean and post-partum hysterectomy 1968-1983," British Journal of Obstetrics and Gynaecology, vol. 93, no. 3, pp. 270-274, 1986.

2. M. E. Akar, E. S. Yilmaz, B. Yuksel, and Z. Yilmaz, "Emergency peripartum hysterectomy," European Journal of Obstetrics Gynecology and Reproductive Biology, vol. 113, no. 2, pp. 178-181, 2004.

3. Kwee, M. L. Bots, G. H. A. Visser, and H. W. Bruinse, "Emergency peripartum hysterectomy: a prospective study in the Netherlands," European Journal of Obstetrics Gynecology and Reproductive Biology, vol. 124, no. 2, pp. 187-192, 2006.

4. G. Daskalakis, E. Anastasakis, N. Papantoniou, S. Mesogitis, M. Theodora, and A. Antsaklis, "Emergency obstetric hysterectomy," Acta Obstetricia et Gynecologica Scandinavica, vol. 86, no. 2, pp. 223-227, 2007.

5. C. Rossi, R. H. Lee, and R. H. Chmait, "Emergency postpartum hysterectomy for uncontrolled postpartum bleeding: a systematic review," Obstetrics and Gynecology, vol. 115, no. 3, pp. 637-644, 2010.

6. Plauché WC, Gruich FG, Bourgeois MO: Hysterectomy at the time of caesarean section. Obstet Gynaecol 1981;58:459_464.

7. O'Brien D, Babiker E, O'Sullivan O, Conroy R, McAuliff F, Geary M, Byrne B: Prediction of peripartum hysterectomy and end organ dysfunction in major obstetric haemorrhage. Eur J Obstet Gynaecol Biol 2010;153:165-169.

8. Henrich W, Surbek D, Kainer F, Grottke O: European Guidelines to treat massive obstetric haemorrhage. J Perinat Med 2008;36:467-478.

9. Plauché WC. Cesarean hysterectomy: Indications, technique, and complications. Clin Obstet Gynecol. 1986; 29: 318-328.

10. Plauché WC. Peripartal hysterectomy. Obstet Gynecol Clin North Am. 1988; 15: 783-795.

11. Kastner ES, Figueroa R, Garry D, Maulik D. Emergency peripartum hysterectomy: Experience at a Community Teaching Hospital. Obstet Gynecol. 2002; 99: 971-975.

12. Bateman BT, Mhyre JM, Callaghan WM, Kuklina EV. Peripartum hysterectomy in the United States: nationwide 14 year experience. Am J Obstet Gynecol. 2012; 206: 63.e1-8.

13. Durfee RB. Evolution of cesarean hysterectomy. Clin Obstet Gynecol 1969;12:575-579.

14. Chanrachakul B, Chaturachinda K, Phuapadit W, Rosingsipragarn R. Cesarean and postpartum hysterectomy. Int J Gynecol Obstet 1996;54:109-113.

15. Sparić R1, Kadija S, Hudelist G, Glisić A, 
Buzadzić S. History of caesarean hysterectomy. Acta Chir Iugosl. 2012;59(1):9-12.

16. Govindappagari S, Wright JD, Ananth CV, et al. Risk of Peripartum Hysterectomy and Center Hysterectomy and Delivery Volume. Obstet Gynecol 2016; 128:1215.

17. Whiteman MK, Kuklina E, Hillis SD, et al. Incidence and determinants of peripartum hysterectomy. Obstet Gynecol 2006; 108:1486.

18. Imudia AN, Awonuga AO, Dbouk T, et al. Incidence, trends, risk factors, indications for, and complications associated with cesarean hysterectomy: a 17-year experience from a single institution. Arch Gynecol Obstet 2009; 280:619.

19. Jakobsson M, Tapper AM, Colmorn LB, et al. Emergency peripartum hysterectomy: results from the prospective Nordic Obstetric Surveillance Study (NOSS). Acta Obstet Gynecol Scand 2015; 94:745.

20. Campbell SM, Corcoran P, Manning E, et al. Peripartum hysterectomy incidence, risk factors and clinical characteristics in Ireland. Eur J Obstet Gynecol Reprod Biol 2016; 207:56.

21. Friedman AM, Wright JD, Ananth CV, et al. Population-based risk for peripartum hysterectomy during low- and moderate-risk delivery hospitalizations. Am J Obstet Gynecol 2016; 215:640.e1.

22. Cromi A, Candeloro I, Marconi N, et al. Risk of peripartum hysterectomy in births after assisted reproductive technology. Fertil Steril 2016; 106:623. 